\title{
Partnering For Pain: a Priority Setting Partnership to identify patient-oriented research priorities for pediatric chronic pain in Canada
}

\author{
Kathryn A. Birnie PhD, Katherine Dib, Carley Ouellette BScN, Mary Anne Dib BCom, Kimberly Nelson, \\ Dolores Pahtayken, Krista Baerg BSN MD, Jill Chorney PhD, Paula Forgeron PhD, \\ Christine Lamontagne MDCM, Melanie Noel PhD, Patricia Poulin PhD, Jennifer Stinson PhD
}

Abstract

Background: Chronic pain affects 1-3 million Canadian children and adolescents and their families. The primary objective of the Partnering For Pain project was to collaboratively identify the top 10 research priorities in pediatric chronic pain.

Methods: Partnering For Pain took a patient-oriented research approach and followed a modified James Lind Alliance Priority Setting Partnership (PSP) to identify the top research priorities in pediatric chronic pain according to people with lived experience (patients), family members and health care providers (clinicians). The PSP was completed in 4 phases between May and December 2018: 1) national survey of stakeholders, including those with lived experience with pediatric chronic pain, family members and clinicians who treat children with chronic pain, to gather priorities, 2) data processing, 3) interim prioritization by invited patients, family members and clinicians (former research participants or identified through pediatric chronic pain programs, patient partner organizations and steering committee member networks) and 4) in-person priority-setting workshop involving patients, family members and clinicians identified via steering committee networks and partner organizations, with evaluation of patient engagement. The process was led by a national steering committee of patient and parent partners, researchers and clinicians engaged in codesign, analysis and translation of project findings.

Results: In phase 1, 215 Canadians (86 patients [40.0\%], 56 family members [26.0\%] and 73 clinicians [34.0\%]) submitted 540 potential priorities that were developed into 112 unique research questions (phase 2). Of the 112 questions, 63 were rated for importance by 57 participants (19 patients [33\%], 17 family members [30\%] and 21 clinicians [37\%]) in phase 3. In phase 4, 20 participants (6 patients [30\%], 6 family members [30\%] and 8 clinicians [40\%]) discussed the 25 most highly rated questions and reached consensus on the final top 10.

Interpretation: The final priorities address pediatric chronic pain prevention, impact and treatment, as well as delivery, access and coordination of care. The priorities reflect a directed and collaborative call to action to improve existing pediatric pain research and care.

Plain language summary: Chronic pain affects 1 in 5 children and teens. This means that $1-3$ million Canadian youth deal with pain lasting months to years. This pain gets in the way of being active, sleeping, going to school, and getting along with friends and family. Youth with chronic pain and their families are experts on what it's like to live with pain, but, until now, research has not asked what issues they care about most. The goal of the Partnering For Pain project was to develop a list of the 10 most important things we still need to learn about chronic pain during childhood according to people who live with it, their families and health care providers. We did this in 4 steps: 1) a survey with 215 people who shared 540 concerns they have about chronic pain in childhood, 2) turning those concerns into questions that can be answered by research, 3) a survey with 57 people who ranked how important each research question was and 4) an in-person discussion with 20 people who chose the top 10 research priorities. Each step included Canadians who have had chronic pain during childhood, their families and health care providers. The final top 10 list has questions about how to better prevent and care for children and teens with chronic pain. These priorities make sure that future research focuses on what is most important to people who will use it in their everyday lives. Project video: https://youtu.be/wA-RwrFiSPk. Project website: www. partneringforpain.com.

hronic pain is increasingly recognized as a public health crisis in Canada owing to its high prevalence, life-long deleterious impact and economic burden. ${ }^{1-5}$ However, often lost in this discussion are the estimated 1-3 million Canadian children with chronic pain, 6,7 who are substantially impaired across important life areas including school, family, friends, sleep, mental well-being and physical
Competing interests: None declared.

This article has been peer reviewed.

Correspondence to: Kathryn Birnie, kathryn.birnie@ sickkids.ca

CMAJ Open 2019. DOI:10.9778/cmajo.20190060 
activity. ${ }^{8-13}$ Forty years ago, it was believed that children were less sensitive to pain, and minimal analgesics were given. ${ }^{14,15}$ It was only through the timely synergy of new science and public outcry that our understanding and treatment of pain in children improved..$^{14,15}$ The field of pediatric pain has grown exponentially since that time, and, although researchers have identified knowledge gaps, ${ }^{16}$ the patient and family voice is largely lacking. Moreover, despite major efforts, treatments for pediatric chronic pain have limited evidence, ${ }^{17-20}$ health care providers receive little pain education, ${ }^{21}$ and most Canadian children cannot access adequate pain care. ${ }^{22-24}$ Thus, there is a dire need to ensure future research is relevant, meaningful and useful to those who need it every day.

Patient engagement is rapidly becoming the norm for health research in Canada. ${ }^{25}$ This includes partnering with patients and families in research planning, governance, conduct and dissemination ${ }^{26,27}$ to enhance research appropriateness, quality and success. ${ }^{28-32}$ Efforts to set chronic pain research priorities in Canada have exclusively or predominantly focused on adults. ${ }^{33,34}$ Children's experiences and concerns (e.g., socioemotional development, parent and family context) are vastly different from those of adults with chronic pain, and the need for specialized pain services for pediatric patients is recognized. ${ }^{12,35}$ Given that chronic pain places children at significantly increased risk for chronic pain and mental health issues into adulthood, ${ }^{36,37}$ attention earlier in the lifespan is warranted. The objective of the Partnering For Pain project is to build capacity for meaningful and sustainable patient and family engagement in pediatric chronic pain research in Canada. ${ }^{38} \mathrm{~A}$ primary goal was to collaboratively identify the top 10 research priorities in pediatric chronic pain. We report the process, outcomes and evaluation of this James Lind Alliance Priority Setting Partnership (PSP).

\section{Methods}

\section{Priority-setting process}

The James Lind Alliance PSP brings together patients, family members and clinicians as equal partners and key stakeholders to identify research priorities in a given area. ${ }^{39}$ The PSP methodology is recognized as robust, strategic, objectively based and inclusive, and as promoting equity in patient voices. ${ }^{26}$ It has been applied to develop research priorities across more than 80 diseases, including adult chronic pain. ${ }^{33,34,40}$ The PSP that we describe focused on pediatric chronic pain, broadly defined as pain in any location from any cause lasting at least 3 months in people younger than 18 years. $^{41}$ The scope of identified priorities could relate to any aspect of pain experience, such as treatment, prevention, diagnosis, assessment, prognosis, service organization and care delivery. Top research priorities were identified through 4 phases: a national survey to gather priorities (phase 1), data processing (phase 2), interim prioritization (phase 3 ) and a workshop to set the final priorities (phase 4). Participants included those living in Canada.

\section{Patient engagement and Partnering For Pain steering committee}

The steering committee overseeing the PSP included crossCanada representation of 2 young adults with lived experience with pediatric chronic pain (K.D., C.O.), 3 parents (M.A.D., K.N., D.P.), 7 pediatric pain nursing, psychology or physician clinicians and/or researchers (K.A.B, K.B., J.C., P.F., C.L., M.N., J.S.) and 1 adult chronic pain clinician (P.P.). ${ }^{38}$ Patient and parent partners were full collaborators ${ }^{26,38}$ and were compensated $^{42,43}$ for their contributions to codesign, execute and translate all phases of the PSP (Table 1). Their involvement enhanced the interpretability, implementation, credibility and reach of the PSP phases and results.

\section{Phase 1: national survey}

A national online survey (Appendix 1, available at www. cmajopen.ca/content/7/4/E654/suppl/DC1) gathered priorities from stakeholders, including those with lived experience with pediatric chronic pain (current children or now adults), family members and clinicians who treat children with chronic pain. Respondents could describe up to 5 priorities in response to open-ended questions. Demographic information was collected. The online survey was codesigned by steering committee members in English and was translated into French by a professional translator. The survey was promoted via social media (Twitter, Facebook, Instagram ${ }^{45}$ ), at pediatric chronic pain programs and other pediatric care centres (postcards, posters, emails), through professional and patient organizations (newsletters, blog posts, emails) and via targeted emails to pediatric clinicians. No incentive was offered for survey completion.

\section{Phase 2: data processing}

Processing of the national survey responses followed James Lind Alliance guidelines..$^{39}$ Out-of-scope submissions (i.e., not about pediatric chronic pain) were determined by at least 2 steering committee members and removed. Single survey responses with multiple research priorities were separated. Eligible responses were categorized based on broad emerging themes to avoid duplication and combine related research questions. When possible, original responses were rewritten into researchable questions with the PICO format (Patient or Population, Intervention, Comparator or Control, and Outcome). To reduce the number of research questions to fewer than 70, as recommended by James Lind Alliance guidelines, ${ }^{39}$ we retained questions that were derived from at least 2 unique survey respondents, at least 1 of whom had lived experience with pediatric chronic pain (patient).

\section{Phase 3: interim prioritization}

We used an interim online survey to reduce the list of research questions to 25-30 questions to be discussed at the priority-setting workshop. ${ }^{39}$ Participants ranked the importance of each research question on a 5-point Likert scale from 1 ("not important") to 5 ("very important"). Demographic information was collected. Targeted email invitations were sent to 156 patients, family members and clinicians who were 
Table 1: Phases of the priority-setting process and steering committee activities

\begin{tabular}{|ll}
\hline Phase & \multicolumn{1}{c}{ Description } \\
\hline 1: national survey (May- & - Online open survey to gather potential \\
August 2018) & priorities with a convenience sample of \\
& people with lived experience with pediatric \\
& chronic pain, family members and health \\
& care providers. \\
- & Survey data were collected and managed \\
& with REDCap electronic data-capture tools \\
& (Vanderbilt University) hosted at The \\
& Hospital for Sick Children. Two to \\
& 6 questions per page were presented over \\
& 4 survey pages, with prompts to complete \\
& required questions and review before \\
submission. Survey was open for 12 wk. & Submissions were screened for duplicate \\
entries based on priority responses; none & were found.
\end{tabular}

2: data processing Steering committee turned national survey (September-October 2018) submissions into unique testable research questions.

Activities of patient and parent partners, and researcher steering committee members

- Survey questions codeveloped by project lead (K.A.B.) and patient and parent partners (K.D., C.O., M.A.D., K.N.), and reviewed by researcher/clinician steering committee members (K.B., J.C., P.F., C.L., M.N., P.P., J.S.).

- Script for promotional video cowritten by project lead (K.A.B.) with patient and parent partners (K.D., C.O., M.D., K.N.).

- Survey promotional materials reviewed and disseminated by all steering committee members. Patient partners (K.D., C.O.) involved in coauthoring newsletter contributions to patient partner and health care organizations.

- Processing responses was conducted by project lead (K.A.B.) and then reviewed by at least 1 patient/parent partner (K.D., C.O., M.A.D., K.N., D.P.) and at least 1 clinician or researcher steering committee member (K.B., J.C., P.F., C.L., M.N., P.P., J.S.) for relevance, accuracy, clarity of wording and duplication.

- French-language submissions were reviewed by bilingual steering committee members (C.L., P.P.) and turned into or combined with English-language research questions, as appropriate.

3: interim prioritization (November 2018)
- Voluntary online closed survey to identify 25-30 most important research priorities with an invited national sample of people with lived experienced with pediatric chronic pain, family members and health care providers.

- Survey data were collected and managed as in phase 1. Nine to 15 questions per page were presented over 6 survey pages (including informed consent page), with prompts to complete required questions and review before submission. Six survey iterations were developed presenting research questions in random order. Respondents were given unique survey link to avoid duplicate entries. Survey was open for 3 wk, with 2 email reminders.

4: priority-setting workshop (Dec. 1, 2018) 1-d in-person workshop to reach consensus on the final top 10 list of research priorities with a national representative invited group of people with lived experience with pediatric chronic pain, family members and health care providers.
- Patient and parent partners (K.D., C.O., M.A.D., K.N. D.P.) identified important areas of representation to ensure diversity of workshop participants (e.g., age, sex, chronic pain experience, geography, family member relationship, health care setting, discipline of health care providers) with input from researchers/ clinicians (K.A.B., K.B., J.C., P.F., C.L., M.N., P.P., J.S.).

- Patient and parent partners (K.D., C.O., M.A.D., K.N., D.P.) participated in workshop.

- Patient and parent partners (K.D., C.O., M.A.D., K.N., D.P.), and researcher/clinician steering committee members (K.B., J.C., P.F., C.L., M.N., P.P., J.S.) involved in codissemination of project findings with project lead (K.A.B.) in peer-reviewed publications, professional and training conferences, and promotional video. ${ }^{45}$ 
former research participants or were identified through pediatric chronic pain programs, patient partner organizations and steering committee member networks. Participants could win 1 of $3 \$ 50$ gift cards for survey completion. We selected and aggregated the 25 most highly ranked research questions from each of the 3 stakeholder groups (patients, family members and clinicians).

\section{Phase 4: priority-setting workshop}

The workshop to set the final priorities was held in person at The Hospital for Sick Children, Toronto. The goal of this 1-day workshop was to reach consensus on the final top 10 research priorities selected from the 25-30 most important questions identified through interim prioritization. ${ }^{39}$ Potential participants were identified via steering committee networks and partner organizations. Invited participants reflected equal representation from patient, family and clinician stakeholder groups, as well as diversity in important areas identified by the steering committee, including age, sex, ethnicity, geographic location, chronic pain condition, care setting and health care profession. Participants completed informed consent and demographic questionnaires at the start of the day. The workshop used a nominal group technique with small-group discussion and rankings with 2 equal multistakeholder groups (90 $\mathrm{min}$ ), followed by whole-group review (30 $\mathrm{min})$, a second round of small-group discussion and rankings $(60 \mathrm{~min})$ and a final whole-group review to reach consensus $(60 \mathrm{~min}) .{ }^{39}$ The workshop was facilitated by an independent consultant with lived chronic disease experience and professional expertise in patient engagement in pain, health care and health research. Travel expenses were covered for participants.

\section{Evaluation}

At the end of the workshop, all participants completed the participant questionnaire from the Public and Patient
Engagement Evaluation Tool version 2.0. ${ }^{46,47}$ The tool includes 13 statements rated on a 5-point Likert scale from 1 ("strongly disagree") to 5 ("strongly agree") and 6 openended questions assessing key elements of quality public and patient engagement: 1) integrity of design and process, 2) influence and impact, 3) participatory culture and 4) collaboration and common purpose. Three questions were added to further evaluate engagement specific to a process of setting research priorities. The Public and Patient Engagement Evaluation Tool includes both outcomes and process metrics of engagement success ${ }^{48}$ and was originally developed with and showed strong usability with patients. ${ }^{46}$ This evaluation is not part of the James Lind Alliance PSP process.

\section{Ethics approval}

Although the James Lind Alliance PSP is conceptualized as service evaluation and development, ${ }^{39}$ consultation with The Hospital for Sick Children Research Ethics Board identified only phases 3 and 4 as research studies, and ethics approval was obtained for these phases.

\section{Results}

Figure 1 provides an overview of results from the PSP. Demographic characteristics for all participant phases are reported in Table 2 .

\section{Phase 1: national survey}

The survey was viewed 527 times and was completed by 217 people (estimated completion rate $41.2 \%$ ). Of the 217,2 were deemed ineligible (researcher or not about pediatric chronic pain). Thus, 215 included people (86 patients [40.0\%], 56 family members [26.0\%] and 73 clinicians [34.0\%]) identified 540 research priorities, with an average of 2.47 priorities (range $1-5$ ) each.

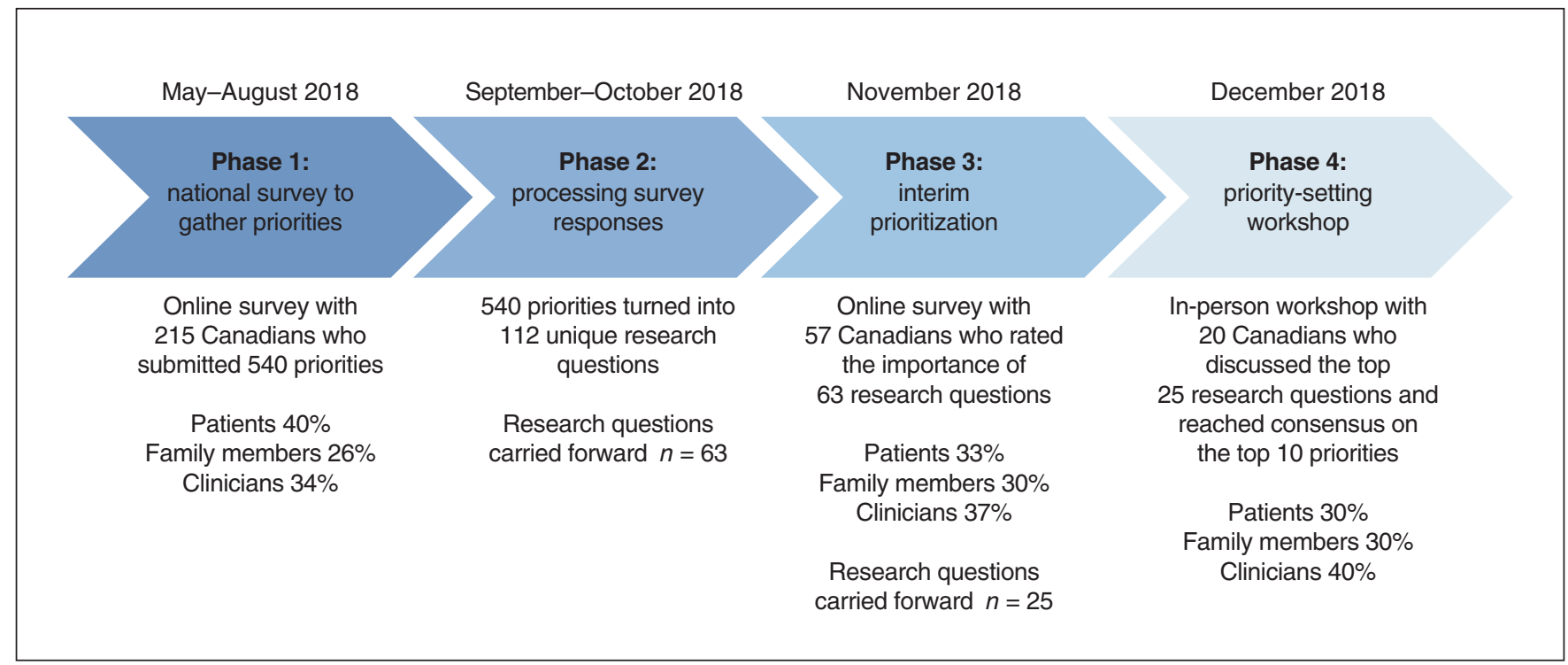

Figure 1: Overview of Partnering For Pain Priority Setting Partnership process. 


\begin{tabular}{|c|c|c|c|}
\hline \multirow[b]{2}{*}{ Characteristic } & \multicolumn{3}{|c|}{ Phase; no. (\%) of participants* } \\
\hline & $\begin{array}{c}\text { 1: national } \\
\text { survey } \\
n=215\end{array}$ & $\begin{array}{c}\text { 3: interim } \\
\text { prioritization } \\
\quad n=57\end{array}$ & $\begin{array}{l}\text { 4: priority-setting } \\
\text { workshop } \\
n=20\end{array}$ \\
\hline \multicolumn{4}{|l|}{ Stakeholder group } \\
\hline $\begin{array}{l}\text { Child/adolescent }<18 \mathrm{yr} \text { with } \\
\text { chronic pain }\end{array}$ & $33(15.3)$ & $6(10)$ & $3(15)$ \\
\hline $\begin{array}{l}\text { Adult } \geq 18 \text { yr with chronic pain } \\
\text { before age } 18\end{array}$ & $53(24.6)$ & $13(23)$ & $3(15)$ \\
\hline Parent/caregiver & $50(23.3)$ & $16(28)$ & $5(25)$ \\
\hline $\begin{array}{l}\text { Other family member } \\
\text { (e.g., sibling) }\end{array}$ & $6(2.8)$ & $1(2)$ & $1(5)$ \\
\hline Physician & $32(14.9)$ & $2(4)$ & $1(5)$ \\
\hline Nurse & $13(6.0)$ & $5(9)$ & $3(15)$ \\
\hline Psychologist & $8(3.7)$ & $6(10)$ & $2(10)$ \\
\hline Physiotherapist & $9(4.2)$ & $4(7)$ & $2(10)$ \\
\hline Social worker & $3(1.4)$ & $2(4)$ & $0(0)$ \\
\hline Occupational therapist & $2(0.9)$ & $2(4)$ & $0(0)$ \\
\hline $\begin{array}{l}\text { Other health care provider in } \\
\text { clinical practice }\end{array}$ & $6(2.8)$ & $0(0)$ & $0(0)$ \\
\hline \multicolumn{4}{|l|}{ Province/territory } \\
\hline British Columbia & $20(9.3)$ & $5(9)$ & $2(10)$ \\
\hline Alberta & $18(8.4)$ & $17(30)$ & $2(10)$ \\
\hline Saskatchewan & $19(8.8)$ & $5(9)$ & $3(15)$ \\
\hline Ontario & $102(47.4)$ & $16(28)$ & $6(30)$ \\
\hline Quebec & $26(12.1)$ & $4(7)$ & $3(15)$ \\
\hline New Brunswick & $2(0.9)$ & $1(2)$ & $0(0)$ \\
\hline Nova Scotia & $16(7.4)$ & $7(12)$ & $3(15)$ \\
\hline Prince Edward Island & $1(0.5)$ & $0(0)$ & $0(0)$ \\
\hline Newfoundland and Labrador & $10(4.6)$ & $0(0)$ & $0(0)$ \\
\hline $\begin{array}{l}\text { Yukon Territory, Northwest } \\
\text { Territories, Nunavut }\end{array}$ & $1(0.5)$ & $2(4)$ & $1(5)$ \\
\hline \multicolumn{4}{|l|}{ Primary language } \\
\hline English & $193(89.8)$ & $53(93)$ & $18(90)$ \\
\hline French & $22(10.2)$ & $4(7)$ & $2(10)$ \\
\hline \multicolumn{4}{|l|}{ Residence } \\
\hline Urban & $179(83.2)$ & $51(89)$ & $17(85)$ \\
\hline Rural & $36(16.7)$ & $6(10)$ & $3(15)$ \\
\hline \multicolumn{4}{|l|}{ Age, yr } \\
\hline Mean \pm SD & $36.23 \pm 14.94$ & $36.58 \pm 15.06$ & $34.70 \pm 15.20$ \\
\hline Range & $14-73$ & $13-71$ & $11-61$ \\
\hline \multicolumn{4}{|l|}{ Sex } \\
\hline Male & $38(17.7)$ & $11(19)$ & $2(10)$ \\
\hline Female & $171(79.5)$ & $46(81)$ & $18(90)$ \\
\hline Prefer not to say & $4(1.9)$ & $0(0)$ & $0(0)$ \\
\hline Prefer to self-describe & $2(0.9)$ & $0(0)$ & $0(0)$ \\
\hline
\end{tabular}




\begin{tabular}{|c|c|c|c|}
\hline \multirow[b]{2}{*}{ Characteristic } & \multicolumn{3}{|c|}{ Phase; no. $(\%)$ of participants* } \\
\hline & $\begin{array}{l}\text { 1: national } \\
\text { survey } \\
n=215\end{array}$ & $\begin{array}{c}\text { 3: interim } \\
\text { prioritization } \\
\quad n=57\end{array}$ & $\begin{array}{c}\text { 4: priority-setting } \\
\text { workshop } \\
n=20\end{array}$ \\
\hline \multicolumn{4}{|l|}{ Ethnicity } \\
\hline White & $187(87.0)$ & $47(82)$ & $12(60)$ \\
\hline Black & $1(0.5)$ & $2(4)$ & $0(0)$ \\
\hline Asian/South Asian & $10(4.6)$ & $4(7)$ & $1(5)$ \\
\hline Arab & $2(0.9)$ & $1(2)$ & $2(10)$ \\
\hline Indigenous & $4(1.9)$ & $1(2)$ & $3(15)$ \\
\hline Mixed/multiple ethnic groups & $5(2.3)$ & $1(2)$ & $2(10)$ \\
\hline Prefer to self-describe & $6(2.8)$ & $1(2)$ & $0(0)$ \\
\hline For patients/family members only & $n=138$ & $n=36$ & $n=12$ \\
\hline \multicolumn{4}{|l|}{ Location of primary chronic pain care } \\
\hline $\begin{array}{l}\text { Specialty pediatric chronic pain } \\
\text { clinic }\end{array}$ & $14(10.1)$ & $18(50)$ & $3(25)$ \\
\hline Pediatric outpatient clinic & $41(29.7)$ & $6(17)$ & $4(33)$ \\
\hline Family doctor/pediatrician & $16(11.6)$ & $5(14)$ & $5(42)$ \\
\hline $\begin{array}{l}\text { Other (e.g., adult pain clinic, } \\
\text { physiotherapy) }\end{array}$ & $26(18.8)$ & $6(17)$ & $0(0)$ \\
\hline None & $41(29.7)$ & $1(3)$ & $0(0)$ \\
\hline \multicolumn{4}{|c|}{ Years you (or family member) have lived with chronic pain } \\
\hline Mean \pm SD & $10.48 \pm 11.67$ & $6.44 \pm 3.82$ & $8.92 \pm 2.54$ \\
\hline Range & $1-55$ & $1-13$ & $3-11$ \\
\hline $\begin{array}{l}\text { For health care providers/ } \\
\text { clinicians only }\end{array}$ & $n=77$ & $n=21$ & $n=8$ \\
\hline \multicolumn{4}{|c|}{ Years you have worked in pediatric chronic pain care } \\
\hline Mean \pm SD & $12.75 \pm 9.96$ & $8.95 \pm 7.61$ & $7.44 \pm 4.94$ \\
\hline Range & $1-40$ & $2-29$ & $3-15$ \\
\hline \multicolumn{4}{|c|}{ Location of primary chronic pain practice } \\
\hline $\begin{array}{l}\text { Specialty pediatric chronic pain } \\
\text { program }\end{array}$ & $20(26)$ & $14(67)$ & $6(75)$ \\
\hline Pediatric outpatient clinic & $22(29)$ & $5(24)$ & $1(12)$ \\
\hline $\begin{array}{l}\text { Other (e.g., school, inpatient, } \\
\text { emergency) }\end{array}$ & $35(45)$ & $2(10)$ & $1(12)$ \\
\hline $\begin{array}{l}\text { Note: } \mathrm{SD}=\text { standard deviation. } \\
{ }^{*} \text { Except where noted otherwise. }\end{array}$ & & & \\
\hline
\end{tabular}

\section{Phase 2: data processing}

Of the 540 survey responses, 19 were excluded for being unclear or a personal story/anecdote or were considered out of scope. The remaining responses were combined into 113 research questions. Based on steering committee feedback, 2 questions were considered duplicates and combined, and 3 questions were reworded for clarity, for a total of 112 unique research questions. Of these, 63 were carried forward for interim prioritization as they were submitted by at least 2 people in phase 1 , at least 1 of whom was a patient.

\section{Phase 3: interim prioritization}

Of the 156 people invited, 66 (42.3\%) viewed the interim survey. Fifty-seven people (19 patients [33\%], 17 family members [30\%] and 21 clinicians [37\%]) completed the survey (survey completion rate $86 \%$ ). Mean importance ratings per research question ranged from 2.94 to 4.50 .

\section{Phase 4: priority-setting workshop}

Twenty participants (6 patients [30\%], 6 family members [30\%] and 8 clinicians [40\%]) attended the workshop to 
discuss the top 25 questions from phase 3 (Appendix 2, available at www.cmajopen.ca/content/7/4/E654/suppl/DC1). Informal input about the top priorities was sought before the workshop from a youth with chronic pain who was unable to attend owing to a pain flare. The final top 10 list is presented in Box 1. During the workshop, 2 questions from the top 25 were combined and simplified (item 3), and 2 questions were reworded (items 4 and 10). Workshop patient engagement evaluations are given in Table 3 .

\section{Interpretation}

National engagement of patients, family members and clinicians identified top patient-oriented research priorities for pediatric chronic pain. The top 10 priorities span the breadth of pediatric chronic pain experience, targeting prevention, impact and treatment, as well as delivery, access and coordination of care. The priorities extend beyond the individual to prioritize involvement, education and change within the broader systems that children with chronic pain live in every day, such as school and health care. Pediatric pain research to date has focused predominantly on its epidemiologic features, intervention and assessment. ${ }^{16}$ The results of this priority-setting process offer a road map to meaningfully extend that work, as well as identify new research avenues and outcomes that remain largely unexplored. Stakeholder evaluations revealed successful execution of quality public and patient engagement.

Consistent with other patient-engaged priority setting in adult chronic pain ${ }^{34}$ and perioperative care, ${ }^{49}$ at the forefront was a focus on prevention of chronic pain. This priority emphasizes understanding underlying mechanisms of pediatric pain, of which there is an identified lack of research, ${ }^{16}$ as well as early intervention through effective management of acute pain. Previous research prioritization in pediatric pain with minimal patient engagement resulted in heavy emphasis on pharmacologic treatments. ${ }^{44}$ Priorities identified through the Partnering For Pain project reflect a biopsychosocial conceptualization with relevance across multimodal (pharmacologic, physical and psychologic) approaches to pediatric chronic pain prevention and treatment. Similar to research priorities for adult chronic pain, ${ }^{33,34}$ mental health and nonpharmacologic treatments, such as physical and psychologic interventions, were highlighted for further investigation. Research in these areas is underway. The quality of existing evidence is low, and treatments do not adequately address all patient-oriented treatment outcomes identified in the PSP. ${ }^{18-20,50,51}$ There is a paucity of clinical drug trials for pediatric chronic pain despite the relative widespread use of drugs, including opioids, ${ }^{17,52-54}$ for which greater research may be warranted to address the priority of improved management of acute pain flares.

Notably, 2 of the top 10 priorities relate to children's education and the school environment. Pediatric pain research has placed minimal focus on pain education for school personnel or investigating effective interventions for supporting school reentry and vocational planning..$^{13,55,56}$ The need for
Box 1: Top 10 patient-oriented research priorities in pediatric chronic pain in Canada, in order of importance

1. What treatments or strategies effectively prevent acute pain from becoming chronic in children and adolescents?

2. What is the impact of living with chronic pain on children's and adolescents' academic performance and educational attainment, and what strategies best support vocational planning for children and adolescents with chronic pain?

3. What physical and psychological treatments are effective for improving pain and function in children and adolescents with chronic pain (for example, functional outcomes including quality of life, depression, fatigue, sleep, acceptance, concentration, resilience, coping, self-management)?

4. What strategies improve access and delivery of evidencebased treatments, and coordination of care, for all Canadian children and adolescents with chronic pain and their families, with a view to reduce disparities?

5. What strategies effectively increase health care providers' training, knowledge, recognition, beliefs, attitudes and communication about the validity and risk of chronic pain in children and adolescents, and its evidence-based treatments?

6. What strategies effectively increase governmental and health care organizational financial support for evidence-based pediatric chronic pain care in Canada?

7. What strategies for educating school personnel about pediatric chronic pain effectively increase their awareness, understanding and recognition of the validity, impact and treatment of pediatric chronic pain?

8. What interventions are effective for managing acute pain flares in children and adolescents with chronic pain?

9. What is the interaction between chronic pain and mental health symptoms in children and adolescents, and when and how can co-occurring chronic pain and mental health symptoms be most effectively diagnosed and treated?

10. When are treatments for chronic pain in children and adolescents most effective (for example, after medical investigation is complete, or variation by type of treatment modality, or readiness of child/adolescent or family to engage in treatment)?

increased pain education for health care providers has also been repeatedly highlighted,,$^{24,34}$ and the topics of nonpharmacologic pain management and pediatric pain are particularly lacking in current medical training. ${ }^{21}$ The invisibility of chronic pain is a reported barrier to empathic and effective patient-partnered care. ${ }^{57}$ Other priorities address concerns related to disparities in access and coordination of evidencebased chronic pain care, particularly for children and families living in rural and remote areas, and from Indigenous communities. ${ }^{58}$ Currently, only 5 Canadian provinces have specialized pediatric chronic pain services. ${ }^{22}$ Direct and indirect costs associated with pediatric chronic pain are high, ${ }^{1,59}$ and there is a need for broader advocacy, increased public awareness and systems-level change.

\section{Limitations}

Although each phase of the priority-setting process included diversity in areas identified as important by patient and parent partners, there is possible underrepresentation based on race and gender, as well as bias in the smaller groups that 


\begin{tabular}{|c|c|}
\hline Item & Mean score \pm SD (range) $\dagger$ \\
\hline \multicolumn{2}{|l|}{ Communications and supports for participation } \\
\hline $\begin{array}{l}\text { I had a clear understanding of the purpose of the } \\
\text { \#PartneringForPain research-priority-setting workshop }\end{array}$ & $4.53 \pm 0.51(4-5)$ \\
\hline $\begin{array}{l}\text { The supports I needed to participate were available } \\
\text { (e.g., travel, child care) }\end{array}$ & $4.68 \pm 0.58(3-5)$ \\
\hline $\begin{array}{l}\text { I had enough information to contribute to the topic } \\
\text { being discussed }\end{array}$ & $4.53 \pm 0.61(4-5)$ \\
\hline \multicolumn{2}{|l|}{ Views and perspectives } \\
\hline I was able to express my views freely & $4.84 \pm 0.37(4-5)$ \\
\hline I feel that my views were heard & $4.74 \pm 0.56(3-5)$ \\
\hline $\begin{array}{l}\text { A wide range of views on the topics discussed was } \\
\text { discussed }\end{array}$ & $4.79 \pm 0.42(4-5)$ \\
\hline $\begin{array}{l}\text { The individuals participating in the \#PartneringForPain } \\
\text { research-priority-setting workshop represented a broad } \\
\text { range of perspectives on the topic }\end{array}$ & $4.79 \pm 0.42(4-5)$ \\
\hline $\begin{array}{l}\text { I feel confident that the final list of top research } \\
\text { priorities identified during the \#PartneringForPain } \\
\text { workshop reflects what matters most to people with } \\
\text { lived experienced with chronic pain as a child or teen, } \\
\text { their family members and treating clinicians }\end{array}$ & $4.53 \pm 0.61(3-5)$ \\
\hline $\begin{array}{l}\text { I feel that my views are reflected in the final list of top } \\
\text { research priorities identified during the workshop }\end{array}$ & $4.53 \pm 0.61(3-5)$ \\
\hline \multicolumn{2}{|l|}{ Impacts and influence of engagement initiative } \\
\hline $\begin{array}{l}\text { I think the \#PartneringForPain research-priority-setting } \\
\text { workshop achieved its objective }\end{array}$ & $4.74 \pm 0.45(4-5)$ \\
\hline $\begin{array}{l}\text { I am confident the input provided through this initiative } \\
\text { will be used by the \#PartneringForPain project team }\end{array}$ & $4.79 \pm 0.42(4-5)$ \\
\hline $\begin{array}{l}\text { I think the input provided through this activity will make } \\
\text { a difference to the work of the \#PartneringForPain } \\
\text { project }\end{array}$ & $4.74 \pm 0.45(4-5)$ \\
\hline $\begin{array}{l}\text { I am confident the input provided through this activity } \\
\text { will direct future research about chronic pain in children } \\
\text { and teens in Canada }\end{array}$ & $4.47 \pm 0.51(4-5)$ \\
\hline \multicolumn{2}{|l|}{ Final thoughts } \\
\hline $\begin{array}{l}\text { As a result of my participation in the } \\
\text { \#PartneringForPain workshop, I am better informed } \\
\text { about what questions people with lived experience with } \\
\text { chronic pain as a child or teen, their family members } \\
\text { and treating clinicians have about treating pediatric } \\
\text { chronic pain in Canada }\end{array}$ & $4.63 \pm 0.50(4-5)$ \\
\hline Overall, I was satisfied with this engagement initiative & $4.74 \pm 0.45(4-5)$ \\
\hline This engagement initiative was a good use of my time & $4.68 \pm 0.48(4-5)$ \\
\hline
\end{tabular}

participated in the interim prioritization and the prioritysetting workshop. Furthermore, patient participants older than 18 years may have been limited in their recall of childhood experiences of chronic pain. Although a large portion of chronic pain care occurs in primary care, ${ }^{1}$ very few primary care providers were engaged. No formal review of existing pediatric chronic pain research was conducted, which makes it likely that some identified priorities have more substantive existing evidence than others.

\section{Lessons from patient engagement}

Patient partners and the project lead (K.A.B.) have previously shared lessons learned in an effort to enhance broader uptake of meaningful youth and family engagement in pediatric pain research..$^{38}$ Our current experience revealed a need to educate and collaborate with institutional research ethics boards regarding the emerging role of patient and parent partners as collaborators versus participants, as well as the value of multiple patient and parent partners to reduce burden, diffuse 
Table 3 (part 2 of 2): Evaluation of patient engagement after the priority-setting workshop*

\begin{tabular}{|c|c|}
\hline Item & Emerging themes \\
\hline \multicolumn{2}{|l|}{ Open-ended questions } \\
\hline $\begin{array}{l}\text { What else would you like us to know about how your } \\
\text { participation in the \#PartneringForPain workshop was } \\
\text { supported? }\end{array}$ & $\begin{array}{l}\text { - Appealing hotel, venue and food } \\
\text { - Well organized and planned } \\
\text { - Facilitators welcoming and created space for respectful } \\
\text { communication } \\
\text { - Collaborative and open environment }\end{array}$ \\
\hline $\begin{array}{l}\text { What else would you like us to know about how you } \\
\text { were able to share your views? }\end{array}$ & $\begin{array}{l}\text { - Respectful environment allowing everyone to be heard and } \\
\text { facilitating compromise } \\
\text { - Small group increased comfort } \\
\text { - Share more details before workshop on earlier-phase results }\end{array}$ \\
\hline $\begin{array}{l}\text { What else would you like us to know about the } \\
\text { influence you think the \#PartneringForPain workshop } \\
\text { will have? }\end{array}$ & $\begin{array}{l}\text { - Hopeful that identified priorities will be acted on } \\
\text { - Desire to know future impact of the results } \\
\text { - Desire for greater political and funding influence } \\
\text { - Belief in credibility of final priorities based on substantive } \\
\text { and authentic engagement of multiple stakeholders }\end{array}$ \\
\hline $\begin{array}{l}\text { What were the strengths of the \#PartneringForPain } \\
\text { workshop? }\end{array}$ & $\begin{array}{l}\text { - Open, warm and welcoming } \\
\text { - Diversity and representation of participants } \\
\text { - Respectful, collaborative and inclusive approach } \\
\text { - Smaller-group discussion effective and efficient } \\
\text { - Inclusion of patient and Indigenous perspectives } \\
\text { - Good communication }\end{array}$ \\
\hline $\begin{array}{l}\text { What could be improved about the \#PartneringForPain } \\
\text { workshop? }\end{array}$ & $\begin{array}{l}\text { - More time for discussion and receiving information earlier } \\
\text { - Suggest } 2 \mathrm{~d} \text {, as long day for people living with pain } \\
\text { - More comfortable chairs } \\
\text { - Round tables for small-group discussion and larger visuals } \\
\text { of questions } \\
\text { - Inclusion of fathers and other clinicians (e.g., social } \\
\text { workers) }\end{array}$ \\
\hline $\begin{array}{l}\text { What else would you like us to know about your } \\
\text { experience with the \#PartneringForPain workshop? }\end{array}$ & $\begin{array}{l}\text { - Rewarding and empowering experience } \\
\text { - Good balance between meeting and connecting with } \\
\text { others, and achieving pragmatic work }\end{array}$ \\
\hline
\end{tabular}

power differentials among the project team and contribute a diversity of perspectives. Our involvement of youth and family members led to different identified priorities compared to prior priority-setting efforts with minimal public or youth involvement. ${ }^{26,44,60}$ Previous priority-setting processes have been criticized for their lack of evaluation. ${ }^{26}$ Integration of evaluation in the workshop revealed areas of strength and improvement for effective patient and family engagement in setting of research priorities (Table 3).

\section{Conclusion}

The final research priorities are a directed call to action. Although Canada is an international leader in pediatric pain research, ${ }^{16,61}$ Canadian research funding for pain is proportionally low compared to that for other acute and chronic disease despite its higher prevalence. ${ }^{62}$ The priority list should be used to inform allocation of research funds to best meet identified needs. Meaningful advancement of these priorities requires continuing and new partnerships across multiple stakeholders, including those involved in the priority-setting process, as well as researchers, government, health care institutions (tertiary and primary care), medical schools, primary schools and the public. Identification of research priorities does not direct the method by which these questions should be investigated, nor does it suggest that other areas are not important. Likely a variety of rigorous approaches are needed across basic and clinical science, ${ }^{16}$ with consideration of implementation and public engagement to reduce the gap from knowledge generation to practice change. ${ }^{29,63-66}$ This will increase the likelihood that research will be effective and efficient, and focused on areas of importance to children with chronic pain and their families.

\section{References}

1. Hogan ME, Taddio A, Katz J, et al. Incremental health care costs for chronic pain in Ontario, Canada: a population-based matched cohort study of adolescents and adults using administrative data. Pain 2016;157:1626-33.

2. Schopflocher D, Taenzer P, Jovey R. The prevalence of chronic pain in Canada. Pain Res Manag 2011;16:445-50.

3. Mann EG, Johnson A, VanDenKerkhof EG. Frequency and characteristics of healthcare visits associated with chronic pain: results from a population-based Canadian study. Can 7 Anaesth 2016;63:411-41. 
4. Shupler MS, Kramer JK, Cragg JJ, et al. Pan-Canadian estimates of chronic pain prevalence from 2000 to 2014: a repeated cross-sectional survey analysis. 7 Pain 2019;20:557-65.

5. Canadian Pain Task Force. Chronic pain in Canada: laying a foundation for action [report]. Ottawa: Health Canada; 2019. Available: https://www.canada.ca/ en/health-canada/corporate/about-health-canada/public-engagement/external -advisory-bodies/canadian-pain-task-force/report-2019.html (accessed 2019 Sept. 20).

6. King S, Chambers CT, Huguet A, et al. The epidemiology of chronic pain in children and adolescents revisited: a systematic review. Pain 2011;152:2729-38.

7. Table 17-10-0005-01: Population estimates on July 1st, by age and sex. Ottawa: Statistics Canada; modified 2019 Apr. 29. Available: https://www150. statcan.gc.ca/t1/tbl1/en/tv.action?pid=1710000501 (accessed 2019 Sept. 20).

8. Forgeron PA, King S, Stinson JN, et al. Social functioning and peer relationships in children and adolescents with chronic pain: a systematic review. Pain Res Manag 2010;15:27-41.

9. Lewandowski AS, Palermo TM, Stinson J, et al. Systematic review of family functioning in families of children and adolescents with chronic pain. 7 Pain 2010;11:1027-38

10. Valrie CR, Bromberg MH, Palermo T, et al. A systematic review of sleep in pediatric pain populations. 7 Dev Behav Pediatr 2013;34:120-8.

11. Palermo TM. Impact of recurrent and chronic pain on child and family daily functioning: a critical review of the literature. 7 Dev Behav Pediatr 2000;21: 58-69.

12. Palermo TM, Valrie CR, Karlson CW. Family and parent influences on pediatric chronic pain: a developmental perspective. Am Psychol 2014;69:142-52.

13. Vervoort T, Logan DE, Goubert L, et al. Severity of pediatric pain in relation to school-related functioning and teacher support: an epidemiological study among school-aged children and adolescents. Pain 2014;155:1118-27.

14. McGrath PJ. Science is not enough: the modern history of pediatric pain. Pain 2011;152:2457-9.

15. Unruh AM, McGrath PJ. History of pain in children. In: McGrath PJ, Stevens BJ, Walker SM, et al., editors. Oxford textbook of paediatric pain. Oxford (UK): Oxford University Press; 2014:3-11.

16. Caes L, Boerner KE, Chambers CT, et al. A comprehensive categorical and bibliometric analysis of published research articles on pediatric pain from 1975 to 2010. Pain 2016;157:302-13.

17. Boulkedid R, Abdou AY, Desselas E, et al. The research gap in chronic paediatric pain: a systematic review of randomised controlled trials. Eur 7 Pain 2018;22: 261-71.

18. Fisher E, Law E, Dudeney J, et al. Psychological therapies for the management of chronic and recurrent pain in children and adolescents. Cochrane Database Syst Rev 2018;(9):CD003968.

19. Kichline T, Cushing CC. A systematic review and quantitative analysis on the impact of aerobic exercise on pain intensity in children with chronic pain. Child Health Care 2019;48:244-61.

20. Hechler T, Kanstrup M, Holley AL, et al. Systematic review on intensive interdisciplinary pain treatment of children with chronic pain. Pediatrics 2015; 136:115-27.

21. Shipton EE, Bate F, Garrick R, et al. Systematic review of pain medicine content, teaching, and assessment in medical school curricula internationally. Pain Ther 2018;7:139-61.

22. Peng P, Stinson JN, Choiniere M, et al. Dedicated multidisciplinary pain management centres for children in Canada: the current status. Can 7 Anaesth 2007; 54:985-91.

23. Lynch ME. The need for a Canadian pain strategy. Pain Res Manag 2011;16: $77-80$.

24. MacDonald NE, Flegel K, Hébert PC, et al. Better management of chronic pain care for all. CMA7 2011;183:1815.

25. Baker GR, McGillion MH, Gavin F. Engaging with patients on research to inform better care. CMA7 2018;190(Suppl):S6-8.

26. Manafo E, Petermann L, Vandall-Walker V, et al. Patient and public engagement in priority setting: a systematic rapid review of the literature. PLoS One 2018; 13:e0193579.

27. Strategy for patient-oriented research — patient engagement framework. Ottawa: Canadian Institutes of Health Research; modified 2019 May 27:1-19. Available: www.cihr-irsc.gc.ca/e/48413.html (accessed 2019 Sept. 20).

28. Brett J, Staniszewska S, Mockford C, et al. Mapping the impact of patient and public involvement on health and social care research: a systematic review. Health Expect 2014;17:637-50.

29. Shen S, Doyle-Thomas KAR, Beesley L, et al. How and why should we engage parents as co-researchers in health research? A scoping review of current practices. Health Expect 2017;20:543-54.

30. Domecq JP, Prutsky G, Elraiyah T, et al. Patient engagement in research: a systematic review. BMC Health Serv Res 2014;14:89.

31. Shippee ND, Domecq Garces JP, Prutsky Lopez GJ, et al. Patient and service user engagement in research: a systematic review and synthesized framework. Health Expect 2015;18:1151-66.

32. Manafo E, Petermann L, Mason-Lai P, et al. Patient engagement in Canada: a scoping review of the 'how' and 'what' of patient engagement in health research [published erratum in Health Res Policy Syst 2018;16:24]. Health Res Policy Syst 2018;16:5.
33. Fitzcharles MA, Brachaniec M, Cooper L, et al. A paradigm change to inform fibromyalgia research priorities by engaging patients and health care professionals. Can 7 Pain 2017;1:137-47.

34. Poulin P, Shergill Y, Romanow H, et al. Researching what matters to improve chronic pain care in Canada: a priority-setting partnership process to support patient-oriented research. Can F Pain 2018;2:191-204.

35. Finley GA, Chorney JM, Campbell L. Not small adults: the emerging role of pediatric pain services. Can 7 Anaesth 2014;61:180-7.

36. Kashikar-Zuck S, Cunningham N, Sil S, et al. Long-term outcomes of adolescents with juvenile-onset fibromyalgia in early adulthood. Pediatrics 2014;133: e592-600.

37. Walker LS, Sherman AL, Bruehl S, et al. Functional abdominal pain patient subtypes in childhood predict functional gastrointestinal disorders with chronic pain and psychiatric comorbidities in adolescence and adulthood. Pain 2012; 153:1798-806.

38. Birnie KA, Dib K, Ouellette C. Co-building a new landscape in pediatric chronic pain research: patient partner and researcher perspectives on meaningful patient engagement. Pediatric Pain Letter 2018;20:21-7.

39. The fames Lind Alliance guidebook version 8. Southampton (UK): James Lind Alliance, National Institute for Health Research Evaluation, Trials and Studies Coordinating Centre, University of Southampton; 2018. Available: www.jla.nihr.ac.uk/jla-guidebook/downloads/Version-8-JLA-Guidebook-for -download-from-website.pdf (accessed 2019 Sept. 20).

40. Top 10s of priorities for research. Southampton (UK): James Lind Alliance, National Institute for Health Research Evaluation, Trials and Studies Coordinating Centre, University of Southampton; 2018. Available: www.jla.nihr. ac.uk/top-10-priorities/ (accessed 2019 Feb. 28).

41. Task Force on Taxonomy of the International Association for the Study of Pain. Classification of chronic pain. 2nd ed. Seattle: IASP Press; 1994.

42. Richards DP, Jordan I, Strain K, et al. Patient partner compensation in research and health care: the patient perspective on why and how. Patient Exper f 2018;5:6-12.

43. SPOR Networks in Chronic Diseases; PICHI Network. Recommendations on patient engagement compensation. Toronto: Toronto General Hospital; 2018. Available: https://diabetesaction.ca/wp-content/uploads/2018/07/TASK -FORCE-IN-PATIENT-ENGAGEMENT-COMPENSATION-REPORT FINAL-1.pdf (accessed 2019 Jan. 27).

44. Liossi C, Anderson AK, Howard RF; NIHR CRN-C CSG in Pain and Palliative Care. Development of research priorities in paediatric pain and palliative care. Br f Pain 2017;11:9-15.

45. Partnering For Pain - Partenaires pour la Douleur. 2018. Available: www. youtube.com/watch?v=dn8g_1vmcWo (accessed 2019 Sept. 20).

46. Abelson J, Li K, Wilson G, et al. Supporting quality public and patient engagement in health system organizations: development and usability testing of the Public and Patient Engagement Evaluation Tool. Health Expect 2016;19: 817-27.

47. Abelson J; PPEET Research-Practice Collaborative. Public and Patient Engagement Evaluation Tool (PPEET), Version 2.0. Hamilton (ON): McMaster University; 2018. Available: https://healthsci.mcmaster.ca/ppe /our-products/public-patient-engagement-evaluation-tool (accessed 2019 Sept. 20)

48. Dukhanin V, Topazian R, DeCamp M. Metrics and evaluation tools for patient engagement in healthcare organization- and system-level decisionmaking: a systematic review. Int 7 Health Policy Manag 2018;7:889-903.

49. Boney $\mathrm{O}$, Bell $\mathrm{M}$, Bell $\mathrm{N}$, et al. Identifying research priorities in anaesthesia and perioperative care: final report of the joint National Institute of Academic Anaesthesia/James Lind Alliance Research Priority Setting Partnership. BMF Open 2015;5:e010006.

50. Vinall J, Pavlova M, Asmundson G, et al. Mental health comorbidities in pediatric chronic pain: a narrative review of epidemiology, models, neurobiological mechanisms and treatment. Children (Basel) 2016;3:40.

51. Hurtubise K, Brousselle A, Noel M, et al. What really matters in pediatric chronic pain rehabilitation? Results of a multi-stakeholder nominal group technique study. Disabil Rebabil 2019 Jan. 7 [Epub ahead of print]. doi: 10.1080/ 09638288.2018.1532462.

52. Wren AA, Ross AC, D'Souza G, et al. Multidisciplinary pain management for pediatric patients with acute and chronic pain: a foundational treatment approach when prescribing opioids. Children 2019;6:33.

53. Gmuca S, Xiao R, Weiss PF, et al. Opioid prescribing and polypharmacy in children with chronic musculoskeletal pain. Pain Med 2019;20:495-503.

54. Harbaugh CM, Lee JS, Hu HM, et al. Persistent opioid use among pediatric patients after surgery. Pediatrics 2018;141:e20172439.

55. Boutilier J, King S. Missed opportunities: school as an undervalued site for effective pain management. Pediatric Pain Letter 2013;15:9-15.

56. Logan DE, Coakley RM, Scharff L. Teachers' perceptions of and responses to adolescents with chronic pain syndromes. F Pediatr Psychol 2007;32:139-49.

57. Paul-Savoie E, Bourgault P, Potvin S, et al. The impact of pain invisibility on patient-centered care and empathetic attitude in chronic pain management. Pain Res Manag 2018;2018:6375713.

58. Julien N, Lacasse A, Labra O, et al. Review of chronic non-cancer pain research among Aboriginal people in Canada. Int 7 Qual Health Care 2018;30: 178-85. 
59. Campbell F, Stinson J, Ouellette C, et al. The association between pediatric chronic pain clinic attendance and health care utilization: a retrospective analysis. Can 7 Pain 2018;2:30-6.

60. Odgers HL, Tong A, Lopez-Vargas P, et al. Research priority setting in childhood chronic disease: a systematic review. Arch Dis Child 2018;103: 942-51.

61. The Expert Panel on the State of Science and Technology in Canada. The state of science and technology in Canada, 2012. Ottawa: Council of Canadian Academies; 2012. Available: https://cca-reports.ca/wp-content/uploads/ 2018/10/stateofst2012_fullreporten.pdf (accessed 2019 Mar. 3).

62. Lynch ME, Schopflocher D, Taenzer P, et al. Research funding for pain in Canada. Pain Res Manag 2009;14:113-5.

63. Wittmeier KDM, Klassen TP, Sibley KM. Implementation science in pediatric health care: advances and opportunities. FAMA Pediatr 2015;169:307-9.

64. Amirav I, Vandall-Walker V, Rasiah J, et al. Patient and researcher engagement in health research: a parent's perspective. Pediatrics 2017;140:e20164127.

65. Curran JA, Bishop A, Chorney J, et al. Partnering with parents to advance child health research. Healthc Manage Forum 2018;31:45-50.

66. Morris ZS, Wooding S, Grant J. The answer is 17 years, what is the question: understanding time lags in translational research. 7 R Soc Med 2011;104: 510-20.

Affiliations: University of Toronto and The Hospital for Sick Children (Birnie, Stinson), Toronto, Ont.; patient partner (K. Dib, M. Dib), Halifax, NS; patient partner (Ouellette), McMaster University, Hamilton, Ont.; parent partner (Nelson), Windsor, Ont.; parent partner (Pahtayken), Onion Lake, Sask.; Department of Pediatrics (Baerg), University of Saskatchewan, Saskatoon, Sask.; Dalhousie University and IWK Health Centre (Chorney), Halifax, NS; University of Ottawa (Forgeron, Lamontagne, Poulin); Children's Hospital of Eastern Ontario (Lamontagne), Ottawa, Ont.; University of Calgary (Noel), Calgary, Alta.; The Ottawa Hospital (Poulin), Ottawa, Ont.
Contributors: Kathryn Birnie primarily conceived the study, in collaboration with Jennifer Stinson. Kathryn Birnie drafted the manuscript, and Katherine Dib, Carley Ouellette, Mary Anne Dib, Kimberly Nelson, Dolores Pahtayken, Krista Baerg, Jill Chorney, Paula Forgeron, Christine Lamontagne, Melanie Noel, Patricia Poulin and Jennifer Stinson revised it critically for important intellectual content. All of the authors contributed to the study design and to the acquisition, analysis and interpretation of the work, approved the final version to be published and agreed to be accountable for all aspects of the work.

Funding: This project was funded by a Patient-Oriented Research Collaboration Grant from the Canadian Institutes of Health Research. It was supported by funding from The Hospital for Sick Children, the Alberta Children's Hospital Research Institute, the Saskatchewan Health Research Foundation, the Children's Hospital of Eastern Ontario Research Institute and the Dalhousie University Faculty of Medicine. Inkind support was provided by the Chronic Pain Network.

Acknowledgements: The authors express gratitude to Cynthia Nguyen, Lauren Harris, Casey McMahon, Adena Cox and Amos Hundert for their project coordination support. They also thank Dawn Richards for facilitating the workshop, and the following people and organizations for their work and support of the Partnering For Pain project: Maria Hudspith and Pain BC, Sandy Smeenk and the ILC Charitable Foundation, and Ayala Gorodzinsky. The authors express appreciation to all the people with lived experience with chronic pain during childhood, family members and clinicians who shared their expertise in contributing to this priority-setting process.

Supplemental information: For reviewer comments and the original submission of this manuscript, please see www.cmajopen.ca/content/7/4/ E654/suppl/DC1. 